\title{
Rancang Bangun Sistem Informasi Akademik untuk Sekolah Menengah (Studi Kasus SMA Nusantara 1)
}

\author{
Aris Martono* ${ }^{*_{1}}$, Ageng Setiani Rafika ${ }^{2}$, Winda Larasati ${ }^{3}$ \\ 'Program Studi Sistem Informasi Universitas Raharja \\ E-mail: *'arismartono@ raharja.info, ${ }^{2}$ agengsetianirafika@ raharja.info,${ }^{3}$ winda@ raharja.info
}

\begin{abstract}
Abstrak
Sistem Informasi Akademik sangat diperlukan saat ini terutama untuk tingkatan sekolah menengah agar pengolahan data-data sekolah yang berhubungan dengan para guru, para siswa, guru, nilai-nilai, mata pelajaran dan lain-lain dapat diolah dengan baik dan tersistem. Permasalahan terjadi bila pada Sekolah Menengah pengolahan datanya masih manual dan belum memiliki sistem informasi akademik. Penelitian ini mengambil studi kasus pada SMA Nusantara 1 yang terletak di daerah Tangerang. Pada sekolah menengah ini saat penelitian dilakukan, sistem informasi akademiknya belum ada dan pengolahan data sekolah masih dilakukan manual sehingga menjadi tujuan penelitian ini untuk membuat sistem informasi akademik sebagai solusi dari permasalahan yang ada saat itu pada sekolah SMA Nusantara 1. Metode penelitian yang dijalankan dengan metode analisa PIECES, dengan metode analisa perancangan menggunakan UML diagram yang berorientasi objek dengan framework Laravel dan database MariaDB. Hasil akhir research ini berupa Sistem Informasi Akademik dengan berbasis Website untuk meningkatkan kinerja pengolahan data pada sekolah menengah yang secara khusus didedikasikan untuk SMA Nusantara 1.
\end{abstract}

Kata Kunci: Sistem Informasi Akademik, Sekolah Menengah, Website.

\section{Abstract}

Academic Information Systems are needed today, especially for the secondary school level so that the processing of school data relating to teachers, students, teachers, grades, subjects and others can be processed properly and systematically. Problems occur when high school data processing is still manual and does not have an academic information system. This research takes a case study at SMA Nusantara 1 which is located in the Tangerang area. At this high school when the research was conducted, the academic information system did not yet exist and school data processing was still done manually so that the purpose of this research was to create an academic information system as a solution to the problems that existed at that time at SMA Nusantara 1. The research method was carried out by the method PIECES analysis, with a design analysis method using object-oriented UML diagrams with Laravel framework and MariaDB database. The final result of this research is a Website-based Academic Information System to improve data processing performance in secondary schools which are specifically dedicated to SMA Nusantara 1.

Keywords: Academic Information System, Middle School, Website.

\section{PENDAHULUAN}

Perkembangan teknologi informasi mempengaruhi dunia pendidikan untuk dapat bergerak mengikuti perkembangan ini terutama untuk sistem sekolah yang terintegrasi, yang dalam hal ini sistem informasi akademik bagi kalangan sekolah menengah. Sistem informasi akademik ini berguna untuk mendukung pengelolaan data kegiatan belajar mengajar di sekolah 
agar terstruktur dan tersistem dengan baik. Penelitian ini mengambil studi kasus pada SMA Nusantara 1 yang terletak di daerah Tangerang yang result observasi dan interview dengan pihak sekolah ditemukan bahwa pengelolaan data sekolahnya masih bisa dibilang sederhana dan dikelola secara manual yang mengakibatkan lambatnya kinerja guru di dalam mengelola data dan memberikan sejumlah informasi yang berkaitan dengan data akademik kepada para siswa, para orang tua dan untuk laporan kepada kepala sekolah. Sistem informasi akademik yang dibuat ini memiliki tujuan sebagai solusi/pemecahan masalah dari masalah-masalah yang muncul dari pengelolaan data sekolah yang dilakukan secara manual dan untuk meningkatkan performa sekolah dan kinerja guru sehingga memudahkan di dalam penyampaian informasi kepada para siswa dan pihak yang memerlukan informasi tersebut. Sistem Informasi Akademik yang dibuat berbasis Website ini sebagai Role System bagi sekolah menengah dan secara khusus dapat diimplementasikan pada SMA Nusantara 1 yang menjadi studi kasus pada penelitian ini.

\section{METODE RISET}

\subsection{Previous Research / Literature Review}

Previous Research / Literature review merupakan pendalaman teori dari penelitianpenelitian yang sudah pernah dijalankan sebelumnya sebagai bentuk masukan serta evaluasi terhadap temuan baru dari penelitian-penelitian tersebut [1]. Previous Research / Literature review ini sebagai sumber referensi dan dukungan terhadap penelitian ini kemudian dikaji, di analisa, di resume dan dijadikan tabel seperti dibawah ini :

Table 1. Previous Research

\begin{tabular}{|c|c|c|c|}
\hline $\begin{array}{l}\text { Nama Penulis dan } \\
\text { Tahun penelitian }\end{array}$ & Judul Penelitian & Platform & Sumber Research \\
\hline $\begin{array}{l}\text { Penelitian dari Siti } \\
\text { Masturoh, Diah } \\
\text { Wijayanti , Arfhan } \\
\text { Prasetyo. } \\
\text { Tahun 2019.[2] }\end{array}$ & $\begin{array}{l}\text { SIA Berbasis Website Menggunakan } \\
\text { metode Waterfall Model di SMK } \\
\text { ITENAS }\end{array}$ & $\begin{array}{l}\text { Berbasis } \\
\text { Website }\end{array}$ & $\begin{array}{c}\text { Diterbitkan pada } \\
\text { Jurnal Informatika } \\
\text { April } 2019\end{array}$ \\
\hline $\begin{array}{l}\text { Penelitian dari } \\
\text { Khaerul Anam, Asep } \\
\text { Taufik Muharram. } \\
\text { Tahun 2018.[3] }\end{array}$ & $\begin{array}{l}\text { Analisa \& Perancangan SIA } \\
\text { berbasis Website pada Madrasah } \\
\text { Islamiyah Al-Mursyidiyyah Al- } \\
\text { Asyirotussyafi'iyyah }\end{array}$ & $\begin{array}{l}\text { Berbasis } \\
\text { Website }\end{array}$ & $\begin{array}{l}\text { Diterbitkan pada } \\
\text { Jurnal Teknik } \\
\text { Informatika } \\
\text { Oktober } 2018\end{array}$ \\
\hline $\begin{array}{l}\text { Penelitian dari Riyadi } \\
\text { Purwanto. } \\
\text { Tahun 2017.[4] }\end{array}$ & $\begin{array}{l}\text { Penerapan SIA untuk Upaya } \\
\text { Peningkatan Efisiensi dan efektifitas } \\
\text { Pengelolaan data Akademik } \\
\text { Sekolah. }\end{array}$ & $\begin{array}{l}\text { Berbasis } \\
\text { Website }\end{array}$ & $\begin{array}{c}\text { Diterbitkan pada } \\
\text { Jurnal Teknologi } \\
\text { Terapan (JTT) } \\
\text { Tahun } 2017\end{array}$ \\
\hline $\begin{array}{l}\text { Penelitian dari M. } \\
\text { Rizki Alpiandi. } \\
\text { Tahun 2016.[5] }\end{array}$ & $\begin{array}{l}\text { SIA berbasis Website pada SMPN } 2 \\
\text { Kec.Gaung Anak Serka. }\end{array}$ & $\begin{array}{l}\text { Berbasis } \\
\text { Website }\end{array}$ & $\begin{array}{l}\text { Diterbitkan pada } \\
\text { Jurnal SISTEMASI } \\
\text { September } 2016\end{array}$ \\
\hline Penelitian dari Melan & Perancangan SIA berbasis Website & Berbasis & Diterbitkan pada \\
\hline
\end{tabular}




\begin{tabular}{|c|l|l|c|}
\hline $\begin{array}{c}\text { Susanti. } \\
\text { Tahun 2016.[6] }\end{array}$ & pada SMK Pasar Minggu Jakarta. & Website & $\begin{array}{c}\text { Jurnal Informatika } \\
\text { Mei 2016 }\end{array}$ \\
\hline $\begin{array}{c}\text { Penelitian dari Yudie } \\
\text { Indrawan, Nanik } \\
\text { Susanti, Wiwit Agus } \\
\text { Triyanto. } \\
\text { Tahun 2016.[7] }\end{array}$ & $\begin{array}{l}\text { Analisa dan Perancangan SIA } \\
\text { sekolah berbasis Web untuk } \\
\text { informasi dan promosi sekolah } \\
\text { kepada masyarakat. }\end{array}$ & $\begin{array}{l}\text { Berbasis } \\
\text { Website }\end{array}$ & $\begin{array}{c}\text { Diterbitkan pada } \\
\text { Jurnal SIMETRIS } \\
\text { April 2016. }\end{array}$ \\
\hline
\end{tabular}

\subsection{Method of Collecting Data}

\section{Metode Observasi}

Dilakukannya Metode Observasi memiliki tujuan untuk mengumpulkan data-data yang diperlukan didalam penelitian, karena observasi merupakan aktivitas ilmiah berdasarkan fakta yang terjadi di lapangan, didapat dengan pengalaman dan memperhatikan kode etik observasi yang berupa: Menghormati martabat manusia, Menghormati privasi dan kerahasiaan serta Menghormati keadilan [8]. Pada penelitian ini observasi dilakukan langsung menuju ke sekolah SMA Nusantara 1 yang berada di daerah Tangerang.

\section{Metode Wawancara}

Untuk metode wawancara dilakukan secara langsung dengan melakukan interview kepada Bpk.Teguh Wijaya,S.Si yang merupakan Stakeholder pada penelitian ini untuk didapatkan informasi mengenai pengolahan data sekolah yang biasa dilakukan pada SMA Nusantara 1.

\section{3. $\quad$ Metode Studi Pustaka}

Untuk metode studi pustaka ini dijalankan dengan cara mengumpulkan sumber-sumber referensi yang berkaitan erat dengan penelitian ini agar penelitian ini kaya akan data dukung yang ilmiah[3]. Sumber referensi dapat berupa buku, jurnal nasional terakreditasi serta literatur lainnya. Dalam melakukan metode studi pustaka ini dijalankan beberapa langkah penelitian kepustakaan seperti mempersiapkan tools/perlengkapan yang dibutuhkan, menyusun secara sistematis Bibliografi kerja, mengatur waktu penelitian, membuat dan membaca catatan Research [9]

\subsection{System Analysis Method}

Untuk System Analysis Method dijalankan metode yang telah dipilih yakni metode analisa PIECES yang melihat aktivitas penelitian dari sisi Performance, Informasi, Economic, Control, Efficiency dan Service [10]. System Analysis Method dengan metode analisa PIECES tergambar pada tabel dibawah ini :

Table 2. Metode Analisa PIECES

\begin{tabular}{|c|c|c|c|}
\hline No. & $\begin{array}{c}\text { Jenis } \\
\text { Analisa }\end{array}$ & $\begin{array}{c}\text { Kelemahan Sistem Yang } \\
\text { Berjalan }\end{array}$ & Sistem Yang Diusulkan \\
& & \\
\hline
\end{tabular}




\begin{tabular}{|c|c|c|c|}
\hline 1. & $\begin{array}{l}\text { Performance } \\
\text { (Kinerja) }\end{array}$ & $\begin{array}{l}\text { Proses pengolahan data sekolah } \\
\text { yang dilakukan secara manual } \\
\text { menyebabkan tidak efisiennya } \\
\text { waktu sehingga laporan yang } \\
\text { dihasilkan menjadi terlambat dan } \\
\text { tidak update. }\end{array}$ & $\begin{array}{l}\text { Pada sistem yang diusulkan } \\
\text { dapat membuat proses akademik } \\
\text { lebih cepat karena sistem yang } \\
\text { dibuat berupa Website Online, } \\
\text { yang dapat diakses dimanapun } \\
\text { dan kapanpun. }\end{array}$ \\
\hline 2. & $\begin{array}{l}\text { Information } \\
\text { (Informasi) }\end{array}$ & $\begin{array}{l}\text { 1. Kualitas dari Informasi yang } \\
\text { diberikan sekolah dan yang } \\
\text { diterima oleh siswa menurun } \\
\text { karena informasi yang } \\
\text { didapatkan tidak tepat waktu. } \\
\text { 2. Informasi dalam bentuk } \\
\text { laporan untuk kepala sekolah } \\
\text { telat dan kurang akurat. }\end{array}$ & $\begin{array}{l}\text { 1. Siswa dapat memperoleh } \\
\text { informasi lebih efektif dan } \\
\text { informasi tersebut tidak akan } \\
\text { hilang/rusak. } \\
\text { 2. Informasi berupa laporan yang } \\
\text { kepala sekolah dapat menjadi } \\
\text { tepat waktu dan akurat, karena } \\
\text { sistem yang mengolah. }\end{array}$ \\
\hline 3. & $\begin{array}{l}\text { Economics } \\
\text { (Ekonomi) }\end{array}$ & $\begin{array}{l}\text { Biaya yang dibutuhkan cukup } \\
\text { banyak untuk pembelian kertas } \\
\text { yang digunakan untuk print out. }\end{array}$ & $\begin{array}{l}\text { Tidak mengeluarkan biaya } \\
\text { banyak untuk dapatkan suatu } \\
\text { informasi, karena dapat diakses } \\
\text { secara online. }\end{array}$ \\
\hline 4. & $\begin{array}{l}\text { Control / } \\
\text { Security } \\
\text { (Keamanan } \\
\text { Aplikasi) }\end{array}$ & $\begin{array}{l}\text { Tingkat keamanan pada sistem } \\
\text { berjalan masih kurang aman } \\
\text { disebabkan pihak yang tidak } \\
\text { berkepentingan dapat } \\
\text { memperoleh informasi dengan } \\
\text { mudah. }\end{array}$ & $\begin{array}{l}\text { Pada sistem yang diusulkan } \\
\text { tingkat keamanan sudah baik, } \\
\text { karena pada sistem ini hanya } \\
\text { dapat diakses oleh yang } \\
\text { mempunyai username dan } \\
\text { password yang sesuai. }\end{array}$ \\
\hline 5. & $\begin{array}{l}\text { Efficiency } \\
\text { (Efisiensi) }\end{array}$ & $\begin{array}{l}\text { Agar menghasilkan suatu } \\
\text { informasi akademik memerlukan } \\
\text { banyak proses dengan banyak } \\
\text { staf yang terlibat untuk } \\
\text { menghasilkan informasi yang } \\
\text { efisien. }\end{array}$ & $\begin{array}{l}\text { Sistem yang diusulkan } \\
\text { mengurangi keterlibatan staf } \\
\text { dalam mengelola suatu } \\
\text { informasi, hanya pihak terkait } \\
\text { yang dapat mengelola informasi } \\
\text { akademik. }\end{array}$ \\
\hline 6. & $\begin{array}{l}\text { Service } \\
\text { (Pelayanan) }\end{array}$ & $\begin{array}{l}\text { Dalam proses pelayanan } \\
\text { akademik saat ini belum } \\
\text { mempermudah siswa dalam } \\
\text { mendapatkan informasi terkait } \\
\text { akademik. }\end{array}$ & $\begin{array}{l}\text { Mempermudah siswa dalam } \\
\text { mendapatkan suatu informasi. }\end{array}$ \\
\hline
\end{tabular}

2.4 Testing Method dengan Black Box Testing 
Untuk testing digunakan Black Box Testing dengan fokus penelitian pada Spec.Fungsi dari Software yang dibuat. Black Box Testing atau nama lainnya Behavioral Testing merupakan metode pengujian yang melihat pada fungsionalitas serta kegunaan Software.[11]

Pengujian dengan Black Box ini hanya menilai pada Spesifikasi dan kebutuhan dari Software yang ada yang telah dibuat, karena adanya pengecekan input dan output sistem tanpa pengetahuan internal (coding) programnya. Pengujian Black Box ini penting dilaksanakan untuk Finding Bug atau gangguan yang mungkin muncul pada Software/aplikasi yang diuji sebelum dirilis secara resmi ke pasaran.[12]

Testing Method dengan Black Box Testing pada penelitian ini sebagai berikut:

Table 3. Testing Method: Black Box Testing

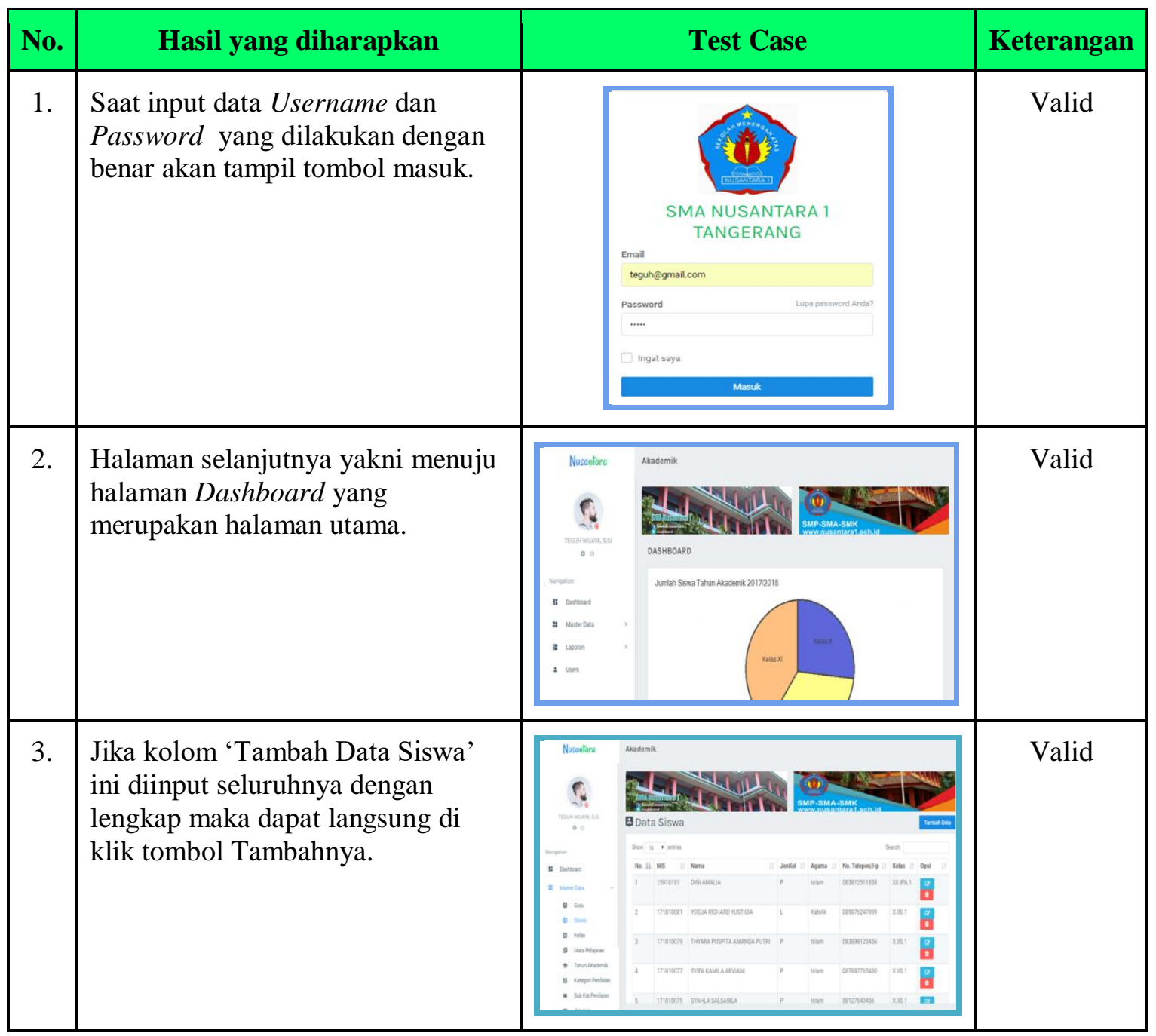




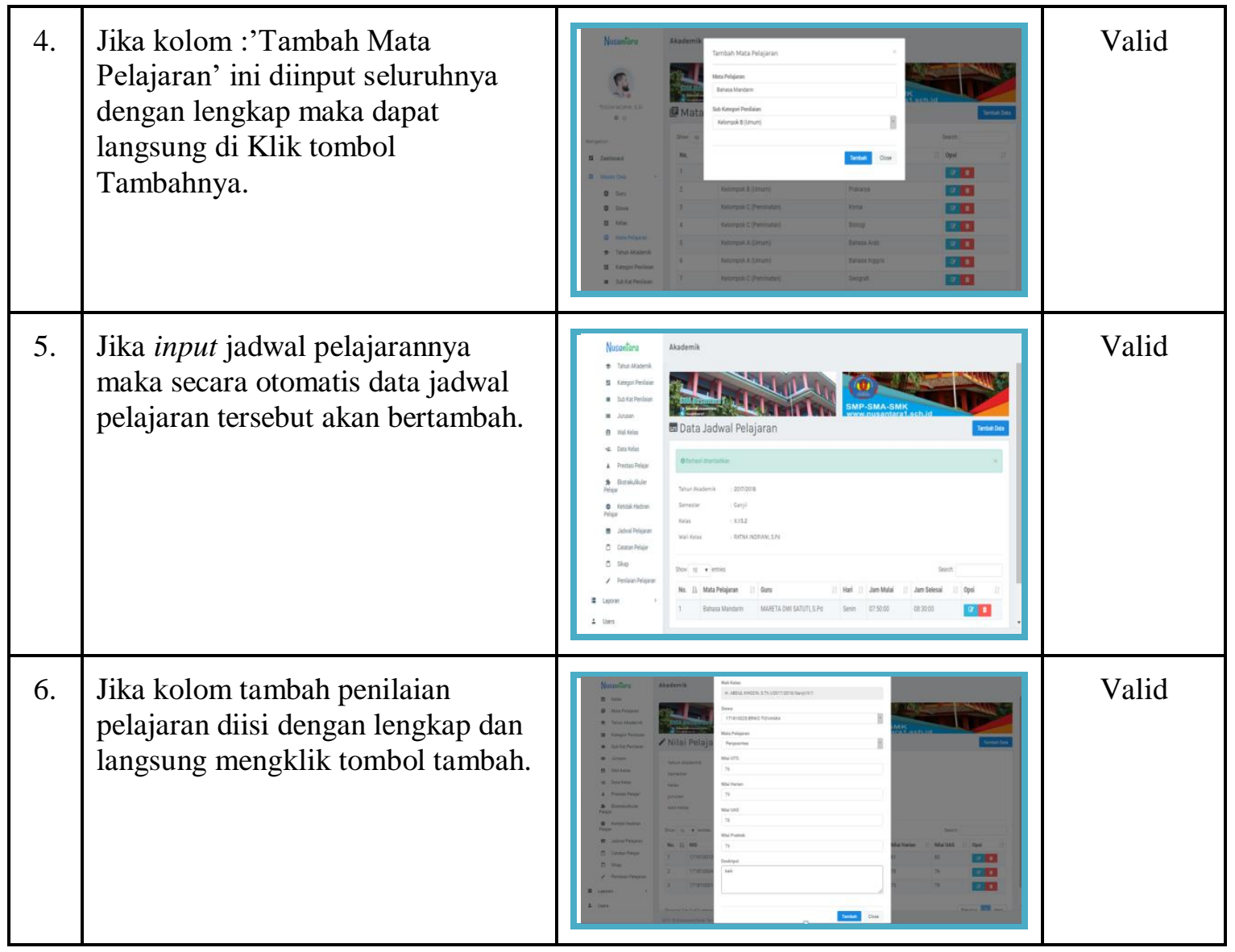

\section{HASIL DAN PEMBAHASAN}

\subsection{Requirement Elicitation}

Requirement Elicitation pada penelitian ini berupa list kebutuhan dari Stakeholder terhadap sistem informasi akademik yang dibuat dengan berbasis Website ini telah diinformasikan dan disetujui oleh Stakeholder SMA Nusantara 1 sehingga sistem informasi akademik ini dapat dilanjutkan dan diimplementasikan pada sekolah tersebut.

\subsection{Analisa Rancangan dengan UML}

Analisa rancangan dengan menggunakan diagram-diagram UML diterapkan pada penelitian ini sebagai tahap analisa detail dari program/website yang dibuat. Adapun diagram yang dimaksud yakni: Use case diagram untuk penggambaran sistem secara global, Sequence diagram untuk penggambaran sistem secara detail, Activity diagram untuk penggambaran aktivitas yang terjadi didalam sistem dan Class Diagram untuk penggambaran database dari program/website yang dibuat.[13]

\subsubsection{Diagram global Use Case}




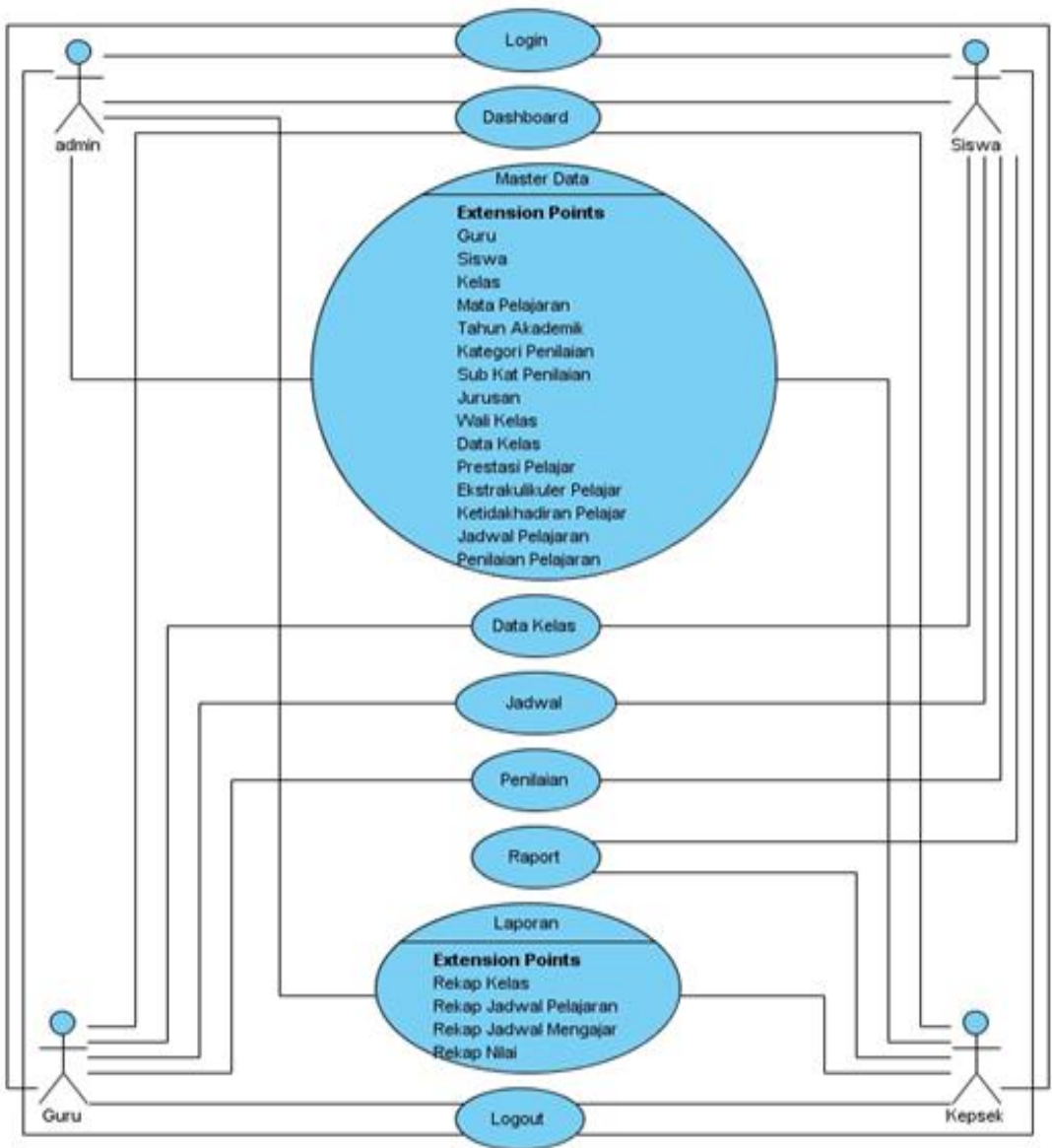

Gambar 1. Use Case Diagram

3.2.2 Diagram Aktivitas/Activity 
ISSN: 2461-1409

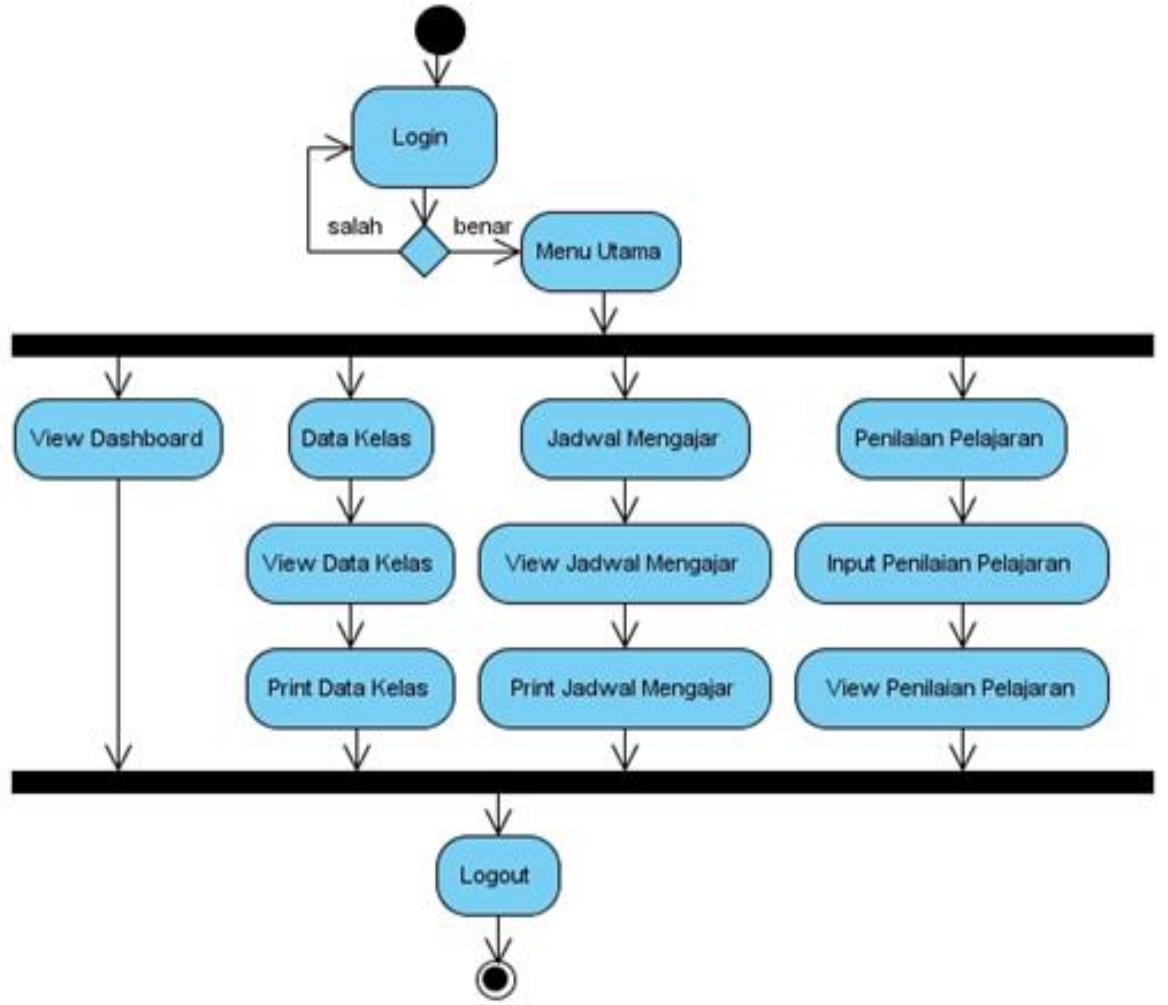

Gambar 2. Activity Diagram

3.2.3 Diagram detail/Sequence

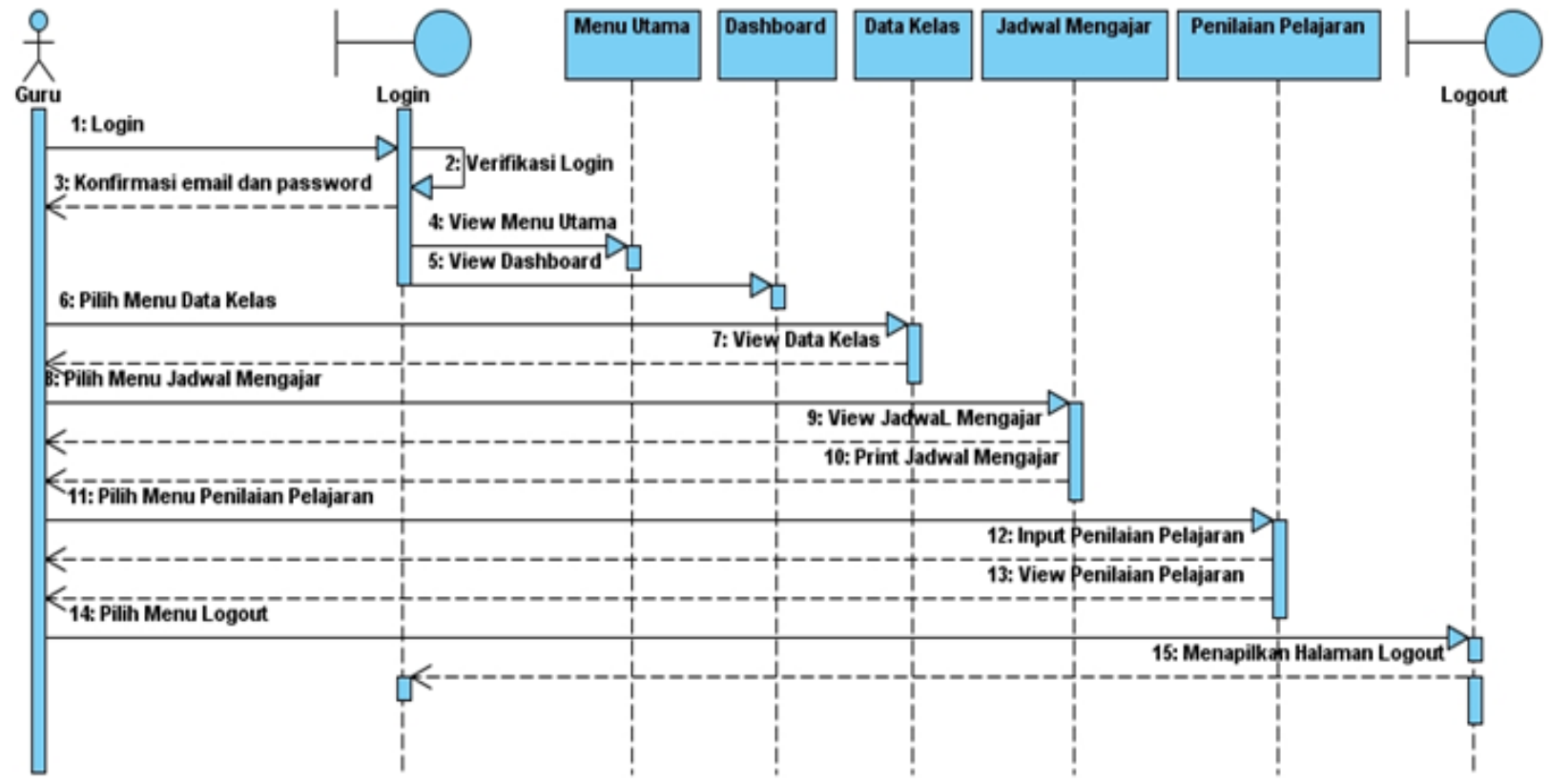

Gambar 3. Sequence Diagram

3.2.4 Diagram Kelas/Class 


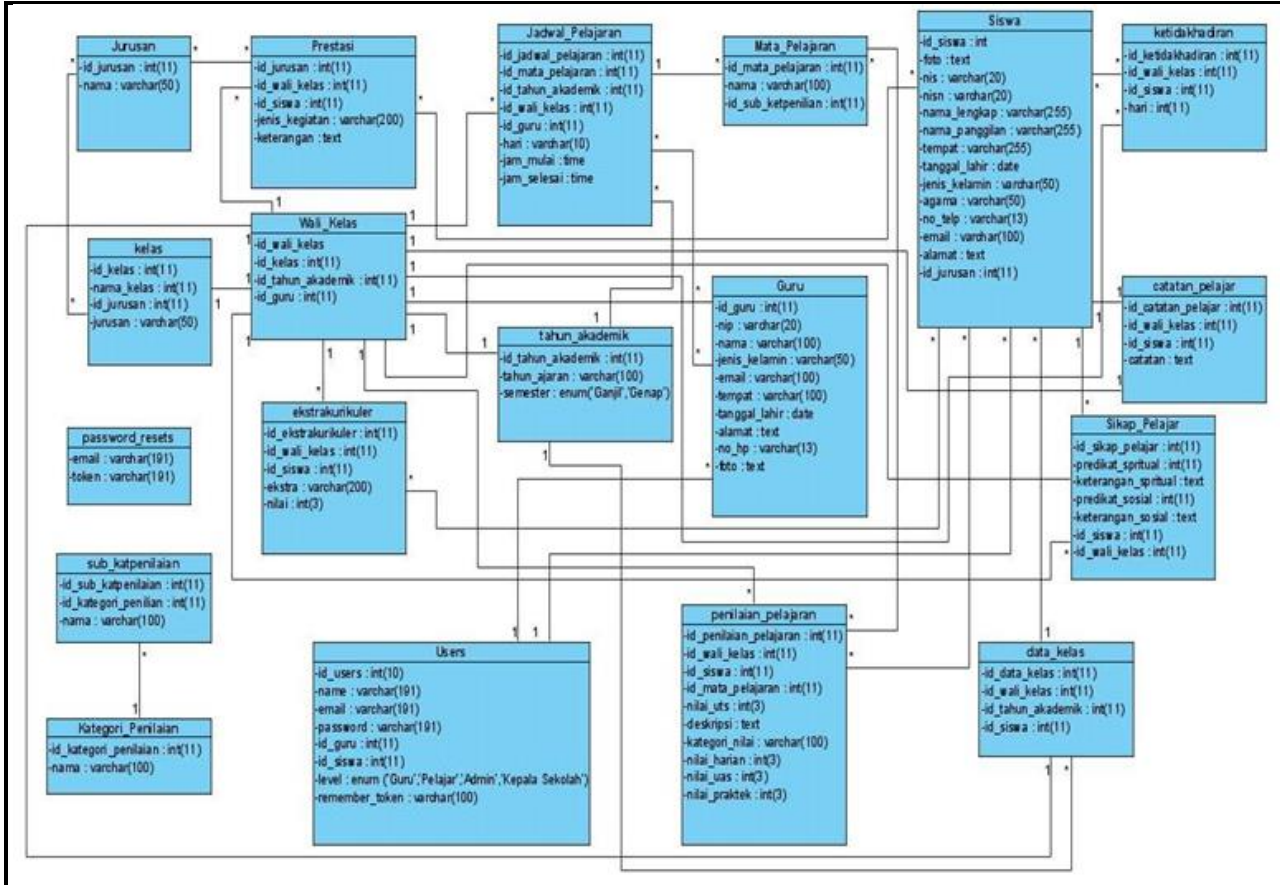

Gambar 4. Class Diagram

\subsection{Implementasi}

Pada implementasi ini akan ditampilkan Halaman Login, lanjut pada Halaman Dashboard, lalu Halaman Data Guru, lanjut pada Halaman Data Siswa, kemudian Halaman Jadwal dan Mata Pelajaran, lalu Halaman Nilai Pelajaran dan Halaman Laporan Rekap Jadwal Pelajaran, yang dapat dilihat detailnya pada pictures di bawah ini :

3.3.1 Gambar halaman untuk Login

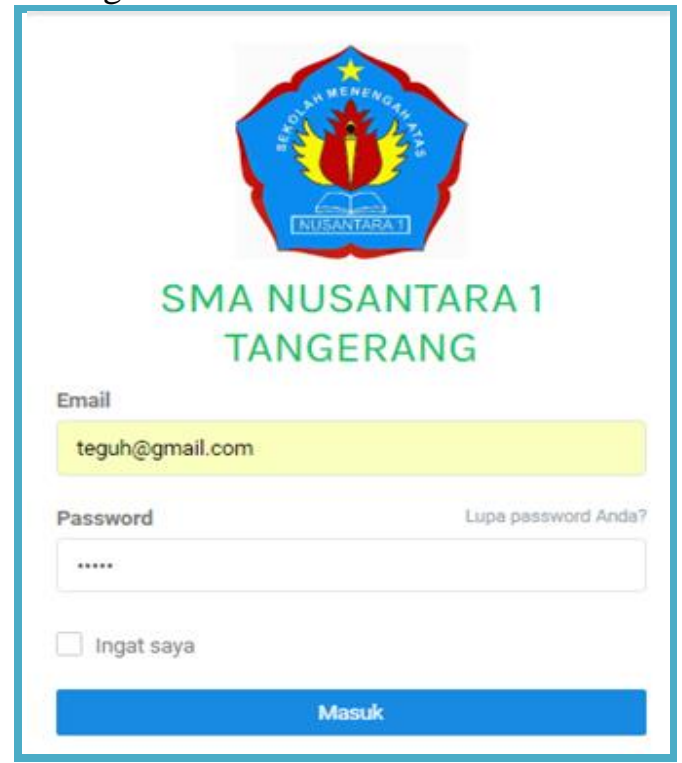

Gambar 5. Login

3.3.2 Gambar halaman untuk Dashboard 


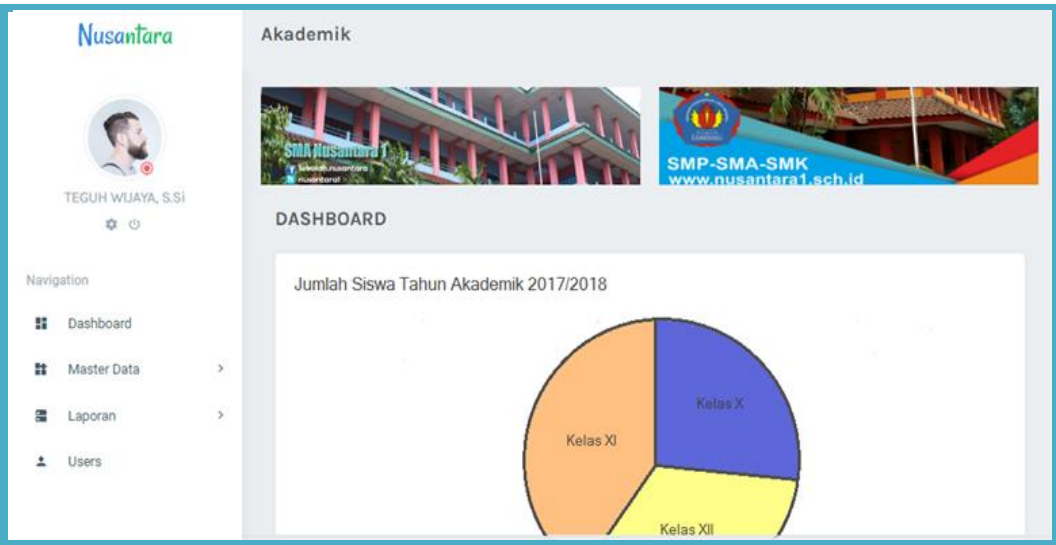

Gambar 6. Dashboard

3.3.3 Gambar halaman untuk Data para Guru

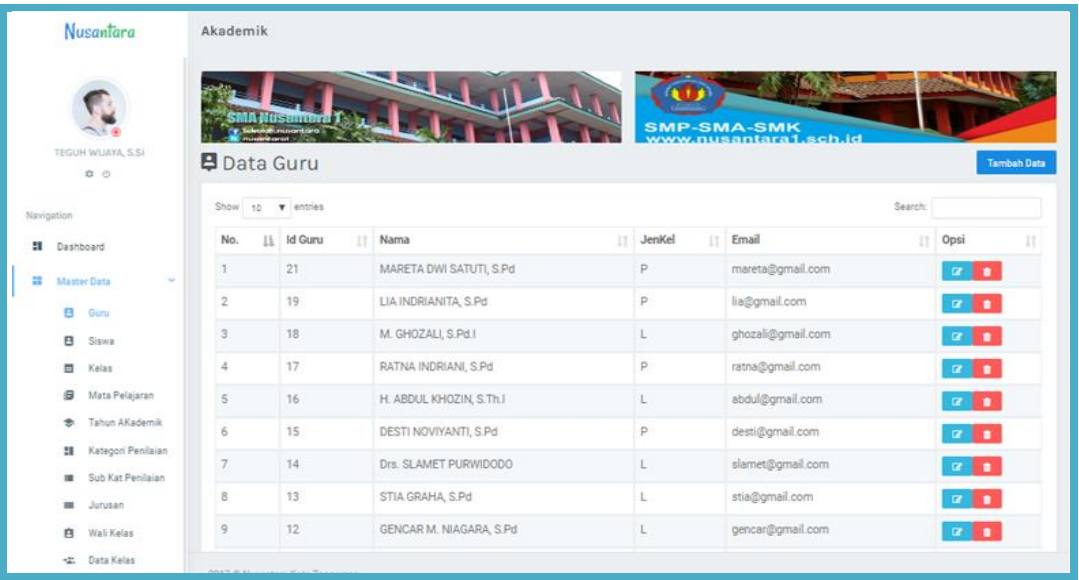

Gambar 7. Data Para Guru

3.3.4 Gambar halaman untuk Data Para Siswa

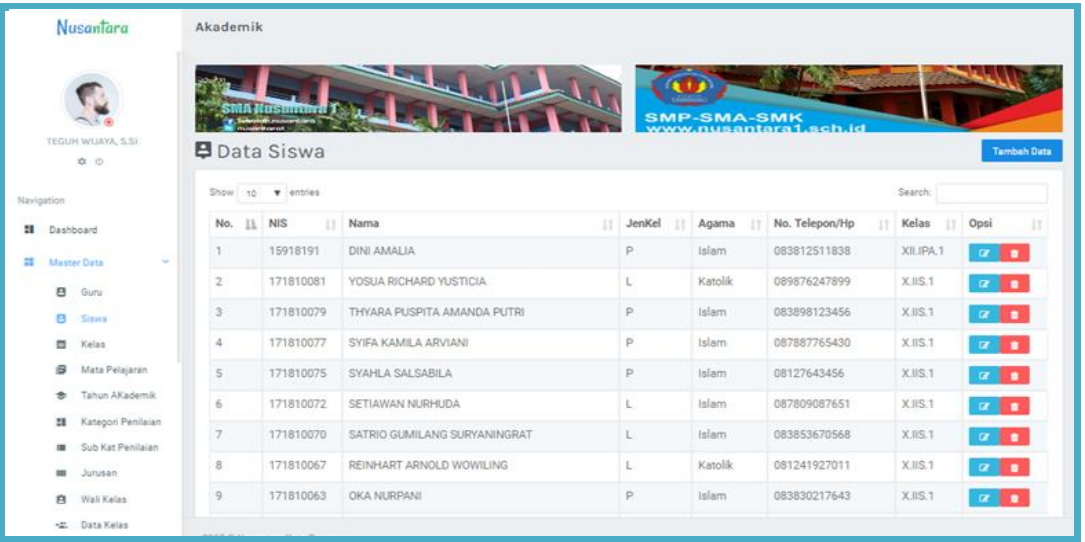

Gambar 8. Data Para Guru

3.3.5 Gambar halaman untuk Data Mata Pelajaran 


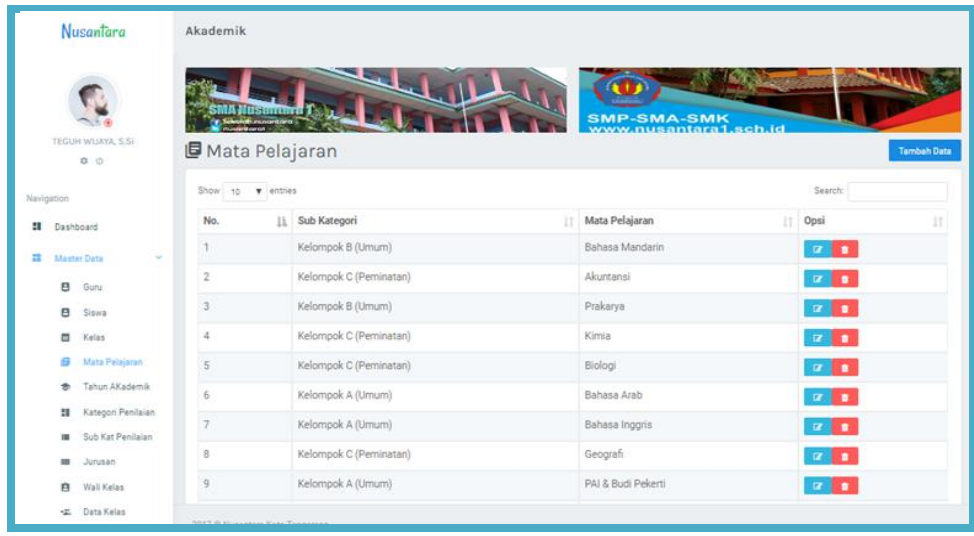

Gambar 9. Data Mata Pelajaran

3.3.6 Gambar halaman untuk Data Jadwal Pelajaran

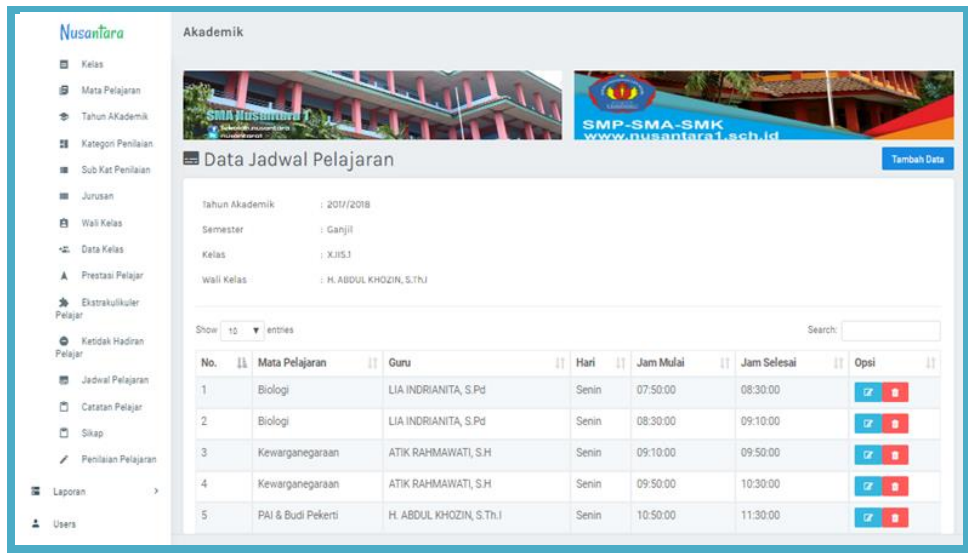

Gambar 10. Data Jadwal Pelajaran

3.3.7 Gambar halaman untuk Nilai Pelajaran

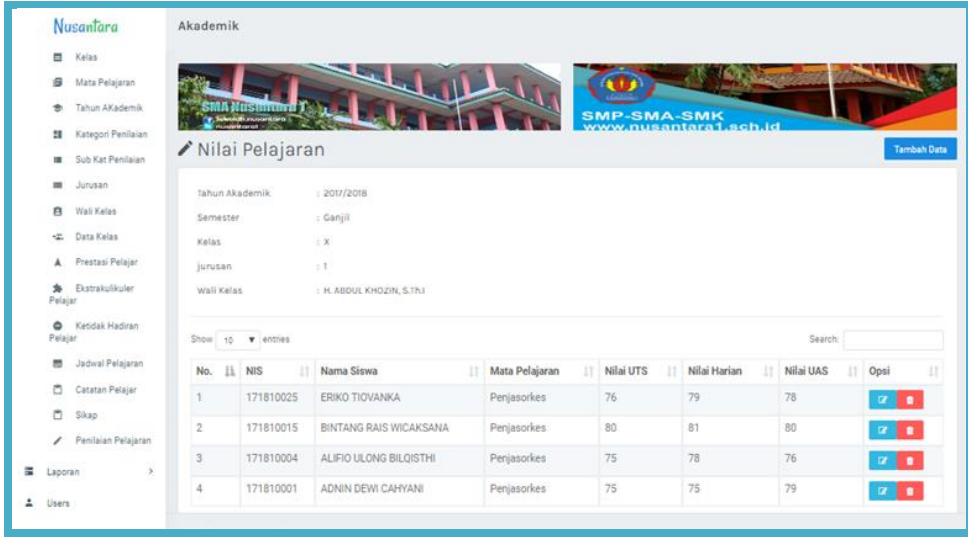

Gambar 11. Nilai Pelajaran

3.3.8 Gambar halaman untuk Rekap Jadwal Pelajaran 


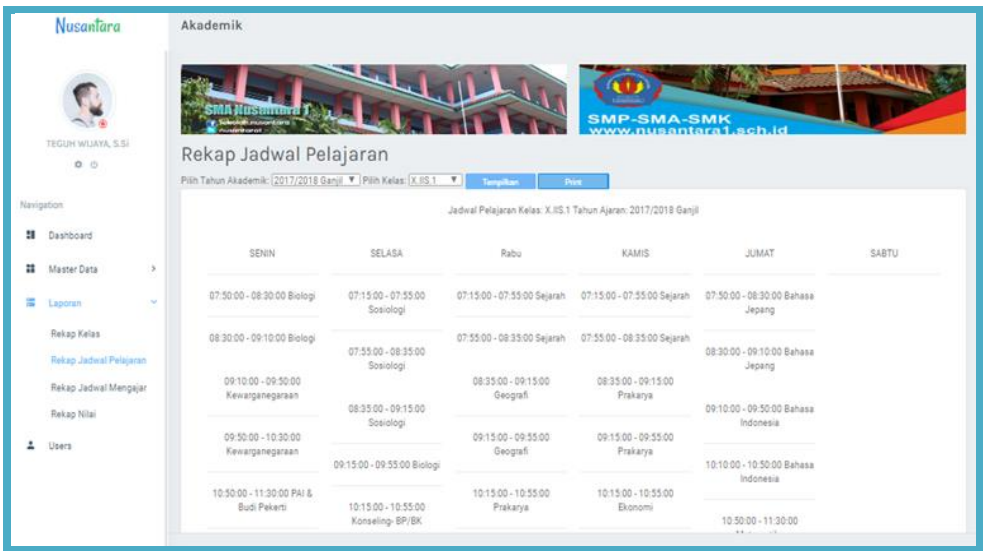

Gambar 12. Rekap Jadwal Pelajaran

\section{KESIMPULAN}

Sistem informasi akademik/SIA yang telah dibuat untuk sekolah menengah ini, yang dalam hal ini mengambil studi kasus pada SMA Nusantara 1 sangat berguna bila diterapkan, sebagai bentuk solusi didalam memecahkan permasalahan pengolahan data sekolah yang sering terjadi karena pengerjaan pengolahan datanya masih manual sehingga memiliki keterbatasan. Untuk penelitian ini, metode yang dijalankan menggunakan metode analisa PIECES yang menjabarkan aktivitas yang berkaitan dengan Performance (P), Information (I), Economic (E), Control (C), Efficiency (E) dan Services (S) untuk diketahui kelemahan dan kelebihannya, kemudian analisa perancangan menggunakan diagram UML yang berorientasi objek dengan framework Laravel dan database MariaDB. Hasil akhir dari penelitian ini berupa Sistem Informasi Akademik dengan berbasis Website untuk meningkatkan kinerja pengolahan data pada sekolah menengah dan yang secara khusus didedikasikan untuk SMA Nusantara 1.

\section{SARAN}

Disarankan agar result dari penelitian yang sudah dibuat ini yakni berupa Sistem informasi akademik berbasis Website untuk sekolah menengah ini dapat dikembangkan lagi menjadi lebih baik, yakni dikembangkan menjadi berbasis Smartphone atau yang lainnya agar tetap memiliki daya guna serta fungsi yang optimal sehingga tetap bermanfaat untuk sekolah menengah di dalam mengolah data sekolahnya.

\section{DAFTAR PUSTAKA}

[1] W. Nashihuddin, F. Suryono, "Tinjauan terhadap kesiapan pustakawan dalam menghadapi disrupsi profesi di era library 4.0: sebuah literatur review". Jurnal Khizanah Al-Hikmah, Vol.6 No.2 Juli-Desember 2018.

[2] S. Masturoh, D. Wijayanti and A. Prasetyo, "Sistem Informasi Akademik Berbasis Web Menggunakan Model Waterfall Pada SMK ITENAS Karawang”. Jurnal Informatika, Vol.6, No.1 April 2019. ISSN: 2355-6579.

[3] K. Anam, A.T. Muharram, "Analisa dan Perancangan Sistem Informasi Akademik berbasis Web pada MI Al-Mursyidiyyah Al-'Asyirotussyafi'iyyah". Jurnal Teknik Informatika, Vol.11, No.2 Oktober 2018. ISSN: 1979-9160.

[4] R. Purwanto, "Penerapan Sistem Informasi Akademik (SIA) sebagai Upaya Peningkatan Efektivitas dan Efisiensi Pengelolaan Akademik Sekolah". Jurnal Teknologi Terapan (JTT) Vol.3, No.2. 2017. ISSN: 2477-3506. 
[5] M.R. Alpiandi, "Sistem Informasi Akademik berbasis Web di SMP Negeri 2 Kecamatan Gaung Anak Serka". Jurnal SISTEMASI Vol.5 No.3. September 2016. ISSN: 2302-8149.

[6] M. Susanti, "Perancangan Sistem Akademik berbasis Web pada SMK Pasar Minggu Jakarta". Jurnal Informatika Vol.3, No.1, Mei 2016. ISSN: 2355-6579.

[7] Y. Indrawan, N. Susanti, W. Agus Triyanto, "Analisa dan Perancangan Sistem Informasi sekolah berbasis Website untuk penyampaian informasi sekolah dan media promosi kepada masyarakat”. Jurnal SIMETRIS Vol.7 No.1. April 2016. ISSN: 2252-4983.

[8] H. Hasanah, "Teknik-teknik observasi (sebuah alternatif metode pengumpulan data kualitatif ilmu-ilmu sosial)", Jurnal At Taqaddum UIN Walisongo, Vol.8, No.1. Juli 2016. ISSN: 19794703.

[9] Sulistiyowati, W. "Peningkatan Hasil Belajar Bahasa Indonesia Materi Wawancara Media Audio-Visual Kelas V MI Jombor Kabupaten Semarang Tahun Pelajaran 2017/2018" (Doctoral dissertation, IAIN Salatiga). 2018.

[10] A.E. Putri, "Evaluasi Program bimbingan dan konseling: sebuah studi pustaka JBKI (Jurnal Bimbingan Konseling Indonesia) Vol.4 No.2 . 2019. ISSN: 2477-5916.

[11] L. Nulhakim, N. Azizah, M.T. Ajija, "Sistem informasi monitoring inventory dengan analisa PIECES pada PT. Care Spunbond. Jurnal SENSITEK, 12 Juli 2018. Pontianak.

[12] T.S. Jaya, "Pengujian aplikasi dengan metode Black Box Testing Boundary Value Analysis (studi kasus: Kantor Digital Politeknik Negeri Lampung). Jurnal Informatika: Jurnal pengembangan IT (JPIT) Vol.03 No.02, Januari 2018. ISSN: 2477-5126.

[13] A. Hendini, "Pemodelan UML sistem informasi monitoring penjualan dan stok barang (studi kasus: Distro Zhezha Pontianak)", Jurnal Khatulistiwa Informatika, Vol. IV No.2. Desember 2016. ISSN: 2339-1928. 